\section{MARKETING ESPORTIVO, CULTURA HIP HOP E CONSUMO: UMA ANÁLISE DA CAMPANHA “É POSSÍVEL!"}

\author{
SPORTS MARKETING, HIP HOP CULTURE AND CONSUMPTION: AN ANALYSIS \\ OF CAMPAIGN "IT'S POSSIBLE!"
}

MARKETING DEPORTIVO, CULTURA HIP HOP Y CONSUMO: UN ANÁLISIS DE LA CAMPANA "¡ES POSIBLE!"

Marcos Godoi*, Maria Angela de Lima Dummel ${ }^{\star *}$, Roberto Boaventura da Silva Sá***

\section{Palavras-chave}

Cultura.

Marketing.

Internet.

Keywords

Culture.

Marketing.

Internet.

Palabras clave

Cultura.

Marketing.

Internet.
Resumo: Nosso objetivo foi analisar os discursos de uma campanha de marketing esportivo na internet. 0 corpus de análise foi composto por: a) informações sobre 0 projeto; b) o manifesto; c) o documentário; d) e 13 comentários de internautas. 0 método baseou-se na Análise de Discurso. 0 tema da campanha é a superação das dificuldades no esporte, na arte e na vida. Nós constatamos uma inter-relação entre os elementos culturais e econômicos, numa associação entre a cultura hip hop, o marketing esportivo e o consumo. Porém, os interlocutores produziram vários e divergentes tipos de resposta.

Abstract: Our goal was to analyze the discourses of an online sports marketing campaign. The corpus of analysis consisted of: a) information about the project; $b$ ) the manifesto; c) the documentary; d) and 13 comments from internet users. The method was based on Discourse Analysis. The campaign' focused on overcoming difficulties in sport, art and life. We found an interrelationship between cultural and economic elements, associating hip hop culture, sports marketing and consumption. However, interlocutors produced various and diverging types of responses.

Resumen: Nuestro objetivo fue analizar los discursos de una campaña de marketing deportivo en Internet. El corpus de análisis consistió en: a) la información sobre el proyecto; b) el manifiesto; c) el documental; d) 13 comentarios de internautas. El método se basa en el Análisis del Discurso. El tema de la campaña es la superación de dificultades en el deporte, en el arte y en la vida. Encontramos una interrelación entre los elementos culturales y económicos, en una asociación entre la cultura hip hop, el marketing deportivo y el consumo. Sin embargo, los interlocutores produjeron diversos y divergentes tipos de respuesta.
*Université de Montréal. QC, Montreal, Canadá.

E-mail: mrgodoi78@ hotmail.com

** União das Escolas Superiores de Rondônia (UNIRON). Porto Velho, Rondônia, Brasil.

E-mail: marrylima1@ hotmail.com

${ }^{* * *}$ Universidade Federal de Mato Grosso. Cuiabá, MT, Brasil.

E-mail: rbventur26@yahoo.com.br

Recebido em: 18-08-2015 Aprovado em: 19-11-2015

(c) (1) (8) Licence 


\section{INTRODUÇÃO}

Este trabalho insere-se na linha dos estudos críticos que analisam o processo de mercadorização do esporte. Em especial, nos interessamos pelo fenômeno da apropriação da cultura hip hop pelo marketing esportivo e sua vinculação com o consumo. Conforme Melo Neto (2003, p. 33) o marketing esportivo é "[...] um tipo de marketing promocional que atua na dimensão institucional, objetivando difundir a marca, melhorar sua imagem e fixá-la melhor na mente do consumidor". Ele atua como mídia participativa, pois o público-alvo participa direta ou indiretamente da atividade esportiva, buscando aliar a propaganda institucional (reforço da imagem) com a promoção de vendas do produto.

Em relação ao hip hop, este é um movimento de cultura juvenil que surgiu no final dos anos 1960 nos Estados Unidos, unindo práticas culturais dos jovens negros e latinoamericanos nos guetos e ruas das grandes cidades (MAGRO, 2002). Ele é constituído pela linguagem artística da música (Rhythm And Poetry - RAP), da dança de rua (break), da arte plástica (grafite) e do basquete de rua (SILVA; CORREIA, 2008). Segundo Magro (2002), no final dos anos 1980, o hip hop e o rap tornaram-se um meio de mobilização e conscientização para os jovens das periferias urbanas brasileiras. Os grupos reivindicavam cidadania e maior participação no mercado de trabalho, além de lutar contra a violência e a discriminação.

Diversos autores têm pesquisado a cultura hip hop sob diferentes enfoques: a estética do basquete de rua e sua relação com a mídia (SILVA; CORREIA, 2008); a possibilidade de inclusão e enfrentamento da discriminação na periferia (WELLER, 2004); as práticas corporais do hip hop como forma de ressignificação da ordem imposta em estéticas híbridas (ROTTA et al. 2002); como lazer e busca da cidadania (STOPPA, 2006); ou ainda a dança de rua como um movimento estético-político de mobilização dos jovens (RECKZIEGUEL; STTIGER, 2005).

No entanto, faz-se necessário compreender melhor os processos que envolvem a cultura hip hop, o marketing e o consumo de produtos esportivos. Assim, o nosso estudo investigou uma campanha de marketing esportivo veiculada pela internet destinada aos jovens das periferias urbanas brasileiras. Nosso objetivo foi analisar criticamente os discursos e estratégias discursivas e ideológicas desta campanha e os comentários dos internautas.

O método baseou-se na Análise do Discurso (AD), e justifica-se porque, conforme explica Orlandi (2003, p. 26): "A Análise do Discurso visa à compreensão de como um objeto simbólico produz sentidos, como ele está investido de significância para e por sujeitos. Essa compreensão, por sua vez, implica explicitar como o texto organiza os gestos de interpretação que relacionam sujeito e sentido". Além disto, a AD pode ser entendida como pesquisas que: estudam corpora "escritos" e formações discursivas que apresentam um interesse histórico; refletem sobre a inscrição do sujeito no discurso; fazem uso das teorias da enunciação linguística; atribuem um papel privilegiado ao interdiscurso (MAINGUENEAU, 2000).

Neste trabalho, entendemos por discurso "[...] uma dispersão de textos cujo modo de inscrição histórica permite definir como um espaço de regularidades enunciativas" (MAINGUENEAU, 2005, p. 15). É uma forma de ação sobre o outro, não apenas uma representação de mundo. Partilhamos a consideração do primado do interdiscurso sobre 0 discurso, ou seja, a unidade pertinente de análise é o espaço de trocas enunciativas entre diversos discursos convenientemente escolhidos. E apesar do discurso ser entendido não apenas como um conjunto de textos, mas também como uma prática discursiva e intersemiótica, 
que integra produções como imagens, fotografias, vídeos, figuras (MAINGUENEAU, 2005), 0 foco desta análise será o discurso verbal. Deste modo, nosso método baseou-se na $A D$, com ênfase na concepção dialógica da linguagem de Mikhail Bakhtin, bem como nas contribuições de Frederick Jameson sobre a cultura de consumo.

É importante notar a compatibilidade teórica entre os autores escolhidos. Bakhtin formulou uma teoria marxista da linguagem, que passou a ser concebida como imanentemente social, ela existe no sujeito e na história, nas práticas cotidianas, nas ações intersubjetivas. Para Bakhtin (1997), o centro organizador de toda enunciação está situado no meio social que envolve o indivíduo, e os conflitos humanos são confrontos entre tendências ideológicas determinadas cultural e historicamente no curso de relações sociais e das lutas que elas envolvem. No curso de suas relações sociais, um grupo organizado cria seus signos ideológicos e, assim, a consciência desses indivíduos adquire forma e existência.

Portanto, para o autor russo, a interação verbal realizada por meio das enunciações constitui a verdadeira substância da língua, tornando a palavra um fenômeno ideológico por natureza, presente em todas as relações entre indivíduos. É possível, assim, observar uma similaridade entre o conceito bakhtiniano de dialogismo e o conceito de interdiscurso de Maingueneau (2000), segundo o qual o discurso só adquire sentido no interior de um universo de outros discursos, lugar no qual ele deve traçar seu caminho. Para interpretar qualquer enunciado, é necessário relacioná-lo a outros enunciados que são comentados, parodiados, citados etc. Já Frederic Jameson é um crítico literário e um teórico político marxista conhecido por sua análise das correntes culturais contemporâneas. Ele descreve o pós-modernismo como uma espacialização da cultura sobre a pressão do capitalismo.

O corpus de análise foi composto por: a) informações sobre o projeto; b) o manifesto; c) 0 documentário; d) e 13 comentários de internautas. A seleção do corpus foi arbitrária, e considerou a pertinência ao objetivo da pesquisa. As informações foram recolhidas no Facebook e no YouTube (NIKE, 2011a; NIKE, 2011b). Os discursos foram transcritos preservando as formas originais, mas os comentários dos internautas não são representativos dos segmentos etários, de sexo, nível educacional ou de classe social, pois esta não é uma pesquisa de campo strictu sensu.

\section{APRESENTAÇÃO E ANÁLISE DO DISCURSO DA CAMPANHA}

\subsection{Informações sobre o projeto}

No dia 7 de setembro de 2011, a empresa Nike lançou o tênis AF1 Brasil, o manifesto e o documentário "É possível!", na Central Única das Favelas (CUFA), de Madureira-RJ, num evento com apresentações de basquete de rua, de $B$-boys e de grafite. Além disso, a empresa divulgou os vídeos do manifesto e do documentário no Facebook' (ver postagens de 15 e 27/09/11) e no YouTube (NIKE, 2011a; NIKE, 2011b). Vale notar a data do lançamento, dia da Independência do Brasil, tanto o manifesto quanto o documentário vão aludir à "independência das ruas". Na época, a Nike criou uma página no Facebook para apresentar informações sobre o projeto, o produto, e os protagonistas: dois jogadores de basquete (Raulzinho e Damiris); três rappers (Emicida, Xará e Pixote); e um grafiteiro (Toddy). Seguem algumas informações: 
O PROJETO: As histórias e os fatos das ruas do Brasil percorrem o mundo. As dificuldades não impedem, muito pelo contrário, são a motivação para incontáveis exemplos de superação. Quem vai à luta, conquista, e a nossa rua conquistou independência.

AIR FORCE 1 BRASIL: Em 1982 o Nike Air Force 1 veio ao mundo trazendo a tecnologia de amortecimento air ao universo do basquete. Em pouco tempo, 0 tênis transcendeu o esporte e se tornou um símbolo das ruas! Quase três décadas depois, este ícone surge para representar uma nova era. Com o manifesto gravado em baixo relevo por todo o calçado e detalhes contrastantes nas cores de nossa bandeira, o AF1 Brasil é o tênis para aqueles que acreditam que é possível!

Sobre a produção de signos, toda imagem artístico-simbólica gerada por um objeto físico (no caso, o tênis) é um signo, que faz parte da realidade material, mas também reflete e refrata uma realidade exterior, assim, todo signo é ideológico (BAKHTIN, 1997). Deste modo, o uso de um tênis " $x$ " pode se tornar um signo (ideológico) de distinção de classe ou grupo social, de juventude, de ser esportivo etc. Nesse sentido, o enunciador lembra que o tênis "AF1" se tornou um signo da juventude urbana e da cultura das ruas nos EUA. Já o tênis "AF1 Brasil", nas cores preta e verde, e com a inscrição "É possível", faz alusão ao verde da bandeira nacional, que significa também esperança. Assim, ele é ressignificado pelos signos não verbais e verbais, como o tênis para aqueles que acreditam que "é possível!".

Com o uso da primeira pessoa do plural - "nossa rua", "nossa bandeira" -, a Nike investe numa aproximação com os moradores das periferias brasileiras. Segundo Maingueneau (2002), o "nós" é usado no discurso para designar um sujeito coletivo; ele é um "eu" expandido para além da pessoa estrita. Além disto, como argumenta Jameson (2001), a dimensão econômica da globalização e a pós-modernidade dissolvem o cultural no econômico e o econômico no cultural. A produção de mercadorias agora é um fenômeno cultural, no qual os produtos são comprados tanto por sua imagem como pelo seu uso imediato. Nesse sentido, surgiu todo um complexo industrial para planejar a imagem das mercadorias e as estratégias de venda.

\subsection{Manifesto "É Possível”}

Bom dia.

A intenção destas palavras é ser como o sol, que invade todos os lugares com a sua luz inaugurando um novo dia. Nós, enquanto soldados de um exército invisível marchamos para o amanhã, como herdeiros do cinza das ruas e filhos de uma realidade que interessa a poucos.

Tendo fé e dor, a paz e a ausência dela, caos e esperança. Somos o nada e desvalorizados como esta palavra, seguimos em frente sem desistir, inconscientemente, sabendo que, um dia, do nada, veio a maior criação de todos os tempos, o universo, através do big-bang.

Somos a crise, que é mãe das soluções mais eficazes, diamantes brutos, essência, poder paralelo, somos o que acontece, fatos, a rua. $\mathrm{O}$ sangue nas artérias e veias da cidade, vítimas da lama que cobre a estrada de tijolos amarelos e impede o mundo de voltar para casa.

Buscando uma luz no fim do túnel, guardada no sorriso de nossas crianças puras, reis Davi perante os gigantes, as dúvidas, conflitos, gigantes mesmo, mas quão maiores, maior a queda, assim como quanto mais sofrida a caminhada maior o sabor da vitória. Sabemos o que é chorar a sós, mas jamais podemos esquecer a beleza de nosso sorriso, tristeza nenhuma tem esse poder. Há um momento entre 
o passado e o futuro, nele está a possibilidade da mudança.

As regras de um asfalto selvagem nos fizeram um em um milhão, mas o amor dos nossos, nos fez um milhão em um. É possível.

(Obs.: grifos como no texto original).

Mesmo sendo uma campanha de marketing, este texto pertence ao gênero "manifesto". Os gêneros do discurso são tipos relativamente estáveis de enunciados que se formam nas diferentes esferas da atividade humana, organizando os conhecimentos sociais e associando as intenções e objetivos dos locutores (BAKHTIN, 2003). O gênero "manifesto" tem uma natureza dissertativa e persuasiva; é uma declaração pública de princípios e intenções com o objetivo de denunciar um problema ou convocar uma comunidade para uma ação.

Podemos inferir que o público-alvo (ou interlocutores) são os jovens moradores das periferias. Neste sentido, é importante notar que, ao escolhermos as palavras de nossos enunciados e o gênero do discurso, partimos das intenções que presidem o seu todo. A situação social mais imediata e o meio social mais amplo determinam a estrutura da enunciação, ou seja, as palavras são orientadas em função do interlocutor e do auditório social (BAKHTIN, 2003).

Em relação à situação deste público-alvo, convém observar que toda política cultural se confronta com uma alternância retórica entre o orgulho da afirmação do grupo cultural e a diminuição estratégica dessa força. Essa política pode ressaltar imagens inspiradoras do heroísmo subalterno (mulheres fortes, heróis negros, a resistência dos colonizados) a fim de encorajá-los; ou pode insistir na miséria e na opressão do grupo para causar indignação, tornar a situação conhecida ou para convencer partes da classe dominante para a causa. Mas, quanto mais se investe na miséria e na impotência, o risco é de fragilizá-los ainda mais (JAMESON, 2001).

Tal alternância retórica pode ser identificada no discurso do manifesto através das definições "nós somos", ora com inferioridade: "filhos de uma realidade que interessa a poucos", "somos o nada e desvalorizados..."; "somos a crise"; "vítimas da lama"; ora com orgulho: "diamantes brutos, essência, poder paralelo, somos o que acontece". Ou ainda, nos sentimentos e sensações expressos: "Tendo fé e dor, a paz e a ausência dela, caos e esperança".

Há no manifesto um dialogismo com o discurso científico da teoria do big bang, por meio de uma comparação: "nós somos o nada"; "do nada, veio a maior criação de todos os tempos"; e também com o discurso bíblico, por meio da história da luta do pequeno rei Davi contra o gigante Golias: "reis Davi perante os gigantes"; além de se referirem como um grupo de "soldados de um exército invisível". Tais metáforas criam dimensões hiperbólicas no discurso.

Por sua vez, o uso do "nós" dá um sentido de coletividade. Porém, paradoxalmente, as sequências "soldados de um exército invisível" e "[...] nos fizeram um em um milhão, [...] nos fez um milhão em um", privilegiam o individualismo. Não se questiona o sistema político econômico, causador das desigualdades e nem o Estado e a sua ausência nas periferias. Diferentemente disso, um dos manifestos mais conhecidos mundialmente, o Manifesto Comunista, publicado em 1848, critica o modo de produção capitalista e busca organizar o proletariado como classe social para reverter sua situação de explorados. Seu slogan final tornou-se célebre: "Proletários de todos os países, uni-vos!" (MARX; ENGELS, 2010, p. 65). 
Sobre o contexto histórico no qual o discurso da campanha foi produzido, 2011 foi um ano marcado por importantes manifestações: "primavera árabe", reivindicando democracia em vários países; o Occupy Wall Street em Nova York; as manifestações contra o sistema políticofinanceiro (Espanha); a oposição às medidas oficiais de austeridade (Grécia); denúncias contra as supostas fraudes na eleição (Rússia); a luta pela educação pública (Chile).

\subsection{Documentário “É Possível”}

O documentário, no ritmo do rap, alterna trechos do manifesto com depoimentos dos protagonistas. Aqui, apresentamos apenas os depoimentos dos personagens.

EMICIDA: Levanta cedo e sai correndo igual um loco aí, tem uma motivação na sua vida pra ver se você não consegue construir essa porra.

PIXOTE: Hoje em dia eu passo aqui assim e vejo que alguma coisa nóis conseguimo, né, mano?

EMICIDA: Eu vou te falar na maior sincera mêmo? A minha vida foi construída por vários desacertos. Tanto bagulho que deu errado, que parecia ter dado errado e no momento conspirou pra fazer parte da construção, tá ligado, mano?

PIXOTE: Mêma coisa eu, acreditei em mim agora tá acontecendo, tá ligado? Não é nem tanto força; é mais ter sede.

EMICIDA: Na real, o nosso esporte é derrubar porta mano. Fazer rap é detalhe, mano.

DAMIRIS: Eu sou uma jovem diferente das minhas amigas, que vão pra balada, que vão pra shopping centers. Minha motivação é tudo que eu passei lá atrás, a minha infância, a minha adolescência quando eu comecei a jogar. Eu coloco isto na frente e não tem adversário que vai conseguir me parar, sabe? Vai ser difícil? Vai, mas eu quero.

RAULZINHO: Tudo aconteceu muito rápido pra mim. Eu tinha 15 anos; eu comecei na equipe adulta do Minas e com 16 eu já fui chamado para a seleção adulta. Pra mim os caras eram os melhores do mundo e eu nunca ia poder chegar nesse nível, mas quando eu fui treinar com eles, e vi que não era uma coisa de outro mundo. É uma coisa que eu tenho potencial pra chegar; sonho em chegar e vou fazer de tudo pra que isso aconteça.

TODDY: A gente vê que dentro de São Paulo há várias São Paulos e aqui é uma delas, né? Talvez o lado B que não foi lembrado. Não tem nenhum espaço cultural aqui, não tem quadra, não tem uma área de lazer. Então foi a partir daí que a gente se interessou, se reuniu. Aqui é o nosso espaço, onde rola diversas atividades culturais aqui. Vem o pessoal da comunidade inteira, a mulecada das ruas próximas estão sempre por aqui. A gente não quer a comoção de ninguém. A gente quer a participação e independe da onde que você venha, do que você faça, protagoniza a tua vida, essa é a nossa ideia aqui.

EMICIDA: O que nóis tentou fazer nesse bagulho foi tipo colocar a essência das coisas que a gente vê na rua memo num texto, tá ligado? Guardar aquilo ali pra quando as pessoas lê esse manifesto; elas sente que elas não tão sozinha. Ninguém vai saber que isto tá organizado e unido e que é uma coisa só, mas cada um dos soldado que tá envolvido nessa causa sabe.

PIXOTE: Soldado de um exército invisível. Pô isso aí é a nossa realidade aqui de São Paulo, tá ligado?

XARÁ: Pô isso daí é que sintetiza a força desse projeto de que não é impossível.

PIXOTE: Tem que ter sede né, mano? Você tem que ter vontade, sede, atitude, tá ligado? 
XARÁ: Atitude é isso daqui, é tudo que eu acumulo nesse plano de mundo.

(Mais para o final do documentário, aparecem imagens de uma partida de basquete de rua na quadra da CUFA com a locução de MCs).

EMICIDA: É calmar o jogo, respirar fundo e pensar... mano, é possível!

TODDY: A gente fala que é possível é isso. A gente tá vivo, independente de tudo aí que acontece a gente tá vivo, não acabou. A história é contínua, vitórias e derrotas, vitórias e derrotas, derrotas, derrotas e uma vitória.

Obs.: grifos nossos.

Como já identificamos acima, o gênero do discurso é o documentário, que se caracteriza pelo compromisso com a exploração da realidade. O filme é em preto e branco, contrastando luz e sombras. Mas há um efeito visual que destaca algumas formas e pessoas na cor verde, visando significar os que acreditam que a vida na periferia "É possível!"; culturalmente, o verde significa esperança.

Além disto, na perspectiva bakhtiniana, todos os enunciados estão fundidos com julgamentos de valor social e tem uma entonação ou tom apreciativo. Assim, podemos identificar entonações apreciativas relacionadas à superação das dificuldades nas sequências: "[...] que parecia ter dado errado e no momento conspirou pra fazer parte da construção", "[...] acreditei em mim, agora tá acontecendo", "Minha motivação é tudo que eu passei lá atrás, [...] e não tem adversário que vai conseguir me parar", "eu tenho potencial pra chegar, [...]".

No discurso em análise há metáforas que comparam o comportamento diante da vida com o esporte: "[...] o nosso esporte é derrubar porta", "calmar o jogo, respirar fundo...", "derrotas e vitórias". Há também metáforas do campo bélico: "exército invisível", "soldados", que estão lutando na "guerra" pela sobrevivência nas grandes cidades.

Logo, o tema do documentário é a superação das dificuldades no esporte, na arte e na vida. O tema é o sentido completo de cada enunciação; através dele é possível entender, do ponto de vista ideológico, as diferenças sutis de significação em enunciados aparentemente semelhantes. Ele é determinado pelas formas linguísticas do enunciado e pelos elementos não verbais da situação (BAKHTIN, 1997). Vale notar as expressões típicas dos jovens da periferia: "mano", "tá ligado", "na maior sincera mêmo", "nóis conseguimo", "pô", aproximando os enunciadores dos interlocutores. Conforme Bakhtin (1998), cada época, cada geração e cada uma das camadas sociais tem sua linguagem social, e são guiadas por princípios orientadores funcionais de conteúdo temático ou sócio-dialetológico.-

Em seu discurso, Toddy denuncia a falta de opções de lazer na periferia. A esse respeito, vale lembrar que as periferias das médias e grandes cidades brasileiras são verdadeiros desertos de equipamentos culturais (Brenner, Dayrell e Carrano 2005). Porém, Toddy não critica diretamente a ausência do Estado na periferia, mas fica subentendido: "talvez o lado B que não foi lembrado".

\section{4 comentários sobre o documentário}

O documentário "É possível" foi postado no YouTube no dia 6 de setembro de 2011, gerando 327.364 exibições e 135 comentários até dezembro daquele ano. Em agosto de 2015 o número de exibições era de 413.612. A escolha da internet como meio de divulgação dessa 
campanha provavelmente se deu pelo aumento considerável de acessos à internet² ${ }^{2}$. Além disto, uma das vantagens do uso da internet é que os vídeos postados primeiramente no YouTube, por exemplo, podem ser "testados" com menor custo de veiculação e com um tempo maior que os 30 segundos convencionais de um comercial para TV, permitindo também medir a aceitação do público-alvo antes de uma possível veiculação em outros meios.

Para esta análise foram selecionados treze comentários de internautas, que foram agrupados por proximidade temática. Antes, é importante dizer que o interlocutor, ao perceber e compreender o significado do discurso do outro, ocupa simultaneamente uma posição responsiva ativa: concorda ou discorda (total ou parcialmente), completa-0, aplica-o, preparase para usá-lo etc. (BAKHTIN, 2003).

Neste sentido, as redes sociais digitais oferecem ao consumidor a possibilidade de interação imediata, de envolvimento participativo com a comunicação gerada pelo anunciante. Ao comentar, ele deixa de ser apenas "alvo", transformando-se também em produtor de conteúdo, e emite, portanto, sua visão de mundo.

Apresentamos a seguir o primeiro grupo de comentários:

Interlocutor 1: Sem hipocrisia"! Essa marca só tênis loko e tal, mas na moral, quantos manos já morreram por causa dessa porcaria? "outro paraplégico por um par de Nike" [...]. Quando a marca começar a fazer algo pela favela (em geral) aí sim eu posso pensar em apoiá-la... $\mathrm{R} \$ 195,00$, é o q sobra pra um brasileiro q ganha um salário e quiser pagar d rico na favela. Vale a pena dar dinheiro pra quem já tem (muito)?

Interlocutor 2: po cara não concordo com voce pois hoje em dia só não compra um nike quem não quer, não sei onde se mora mais aqui na cidade Tiradentes vejo um monte de muleke que comprou com trampo e não deixou de ajudar o pai e a mãe, não acho que eles querem pagar de rico mais em termos de qualidade a nike é muito superior a qualquer tenis nacional, pelo menos nos tenis de skate, desses eu entendo porque ando.

Interlocutor 3: é possivel o q? somos o nada e é impossivel alguem da minha quebrada compra um tenis de $\mathrm{R} \$ 350,00$ sem passa fome no fim do mês!! quando for criar um tenis das ruas pense em quem verdadeiramente tah nelas, não nos play boy riquinho... salve emicida, pixote sou fã!! mas essa foi mancada.

Estes comentários abordam as temáticas do poder de compra, da qualidade e dos significados de se usar o produto. Alguns interlocutores concordam e outros discordam que a população da periferia possa comprar o produto. Conforme Bakhtin (1997), em cada contexto sócio-histórico, grupos de objetos particulares ganham atenção especial e um valor particular. Para que esse objeto entre no horizonte social do grupo e desencadeie uma reação semióticoideológica é fundamental que ele esteja ligado às condições socioeconômicas do grupo, ou seja, às bases de sua existência material.

Em relação ao consumo, há uma dimensão da globalização econômica denominada "cultura do consumo", desenvolvida primeiramente nos EUA e em outros países desenvolvidos, mas sistematicamente espalhada pelo mundo. Essa cultura produz uma modalidade específica de vida, gerada pela produção de mercadorias no capitalismo tardio, que ameaça consumir formas alternativas de comportamentos culturais, mas que pode ser objeto de formas de resistência (JAMESON, 2001), como podemos observar em alguns comentários. 
No que tange à renda dos brasileiros, os dados divulgados no Censo 2010 contrastam com a imagem difundida de que o Brasil está se tornando um país desenvolvido e que está erradicando a pobreza. Ainda que nos últimos anos os indicadores sociais tenham melhorado, $50 \%$ da população tinham uma renda que não ultrapassava $R \$ 375,00$ (BAVA, 2011).

A seguir, apresentamos mais três comentários:

Interlocutor 4: Poha, da hora o video, muito bem feito, retrata ae uma parte da sociedade que só é vista por quem realmente vive ela, e pra quem não vive, é vendo isso que a gente sente (:

Interlocutor 5: 0 rap cada vez melhor, como o Projota diz: Rap nacional é foda vai tomar tudo de uma vez, só não dominamos o mundo ainda porque não falamos inglês! A rua é Nóiz.

Interlocutor 6: Faço parte dessa guerra também, sou um dos soldados!! Só queria conseguir fazer algo para mudar esses sistema em que vivemos, fico envorgonhado as vezes de mim por não conseguir tomar pequenas atitudes..... Mas o video show de bola... Sou guerreiro também, faço parte dessa luta, [...]. Viva o Hip Hop.

Os interlocutores concordam e elogiam o documentário. Logo, ele foi eficaz ao reproduzir os signos da cultura hip hop e a realidade da periferia, permitindo uma identificação de um contingente de interlocutores. 0 interlocutor 5 , por exemplo, chama a atenção para a questão da hegemonia cultural dos EUA. Já 0 interlocutor 6 lamenta não poder mudar 0 sistema, o que pode ser indício de uma adesão às ideologias que privilegiam o individualismo em detrimento dos movimentos sociais e ações coletivas para transformar a sociedade.

Vejamos agora mais um grupo de comentários:

Interlocutor 7: Legal ein, tão na Rolling Stone, parceria com a Nike... pena que a panela ganha e a favela pena. Os popstar do rap brasileiro tão bem na fita, espero que não estejam se vendendo barato... mas cada um com sua realidade.

Interlocutor 8: Agora só faltava essa, a nike representar a rua "E a nossa rua conquistou a independência". Não fode, a nike é um produto de burguês, e outra admiro o emicida e o pixote, que ficam pagando uma de revolucionários e assinam contrato com a nike. Vale ressaltar que a nike explora a mão de obra escrava na Indonésia, onde crianças de 12 anos, trabalham em turno de 12hs, por um baixo custo. Isso é representar a rua??

Interlocutor 9: Não é um pouco ingênuo continuar esse discurso de que as grandes marcas estão erradas em se infiltrar na cultura popular e/ou de rua do Brasil? Por que nos EUA essas marcas podem se associar com áreas consideradas pobres e perigosas como o Bronx, Harlem, South Central, mas no Brasil são duramente criticadas por entrar no gueto? [...].

Interlocutor 10: sobre exploração de trabalho semi-escravo, sua informação está desatualizada. as grandes marcas de calçado, nos últimos anos, têm sido vigiadas de perto e pressionadas a mudar suas práticas, o que tem surtido efeito. todas as grandes têm um setor chamado "Social and Envirorment Affairs", que fiscaliza fornecedores, documentação de funcionários, situação das fábricas, horas trabaIhadas, segurança e outros itens. [...].

É importante notar que o discurso escrito é parte de uma discussão ideológica em grande escala; ele pode responder alguma coisa, refutar, antecipar as respostas e objeções potenciais, procurar apoio etc. (BAKHTIN, 1997). Assim, os interlocutores 7 e 8 rejeitam a campanha num tom irônico. 0 interlocutor 7 "elogia" os rappers por estarem na revista Rolling Stone e serem parceiros da Nike, mas os desqualifica por estarem se vendendo. 0 interlocutor 
8 refuta a legitimidade da Nike em representar a periferia por seu histórico de exploração de mão de obra escrava e infantil (NA COLA..., 2010). De sua parte, o interlocutor 9 concorda com o discurso do documentário, defendendo a marca por ajudar a comunidade e achando justo esse tipo de marketing. Em resposta à acusação de exploração do trabalho infantil, o interlocutor 10 informa sobre a vigilância em torno das grandes marcas, por inferir que seu interlocutor desconhecesse esse fato. Conforme Bakhtin (2003), o enunciador sempre leva em conta a percepção do seu discurso pelo destinatário: se ele dispõe de conhecimentos sobre o assunto; suas concepções, convicções, preconceitos, simpatias e antipatias, pois tudo isto determinará a sua compreensão responsiva.

Segue abaixo o último agrupamento de comentários:

Interlocutor 11: Se não tem uns trampos como esse ae que fode tudo de vez memu. Ae vcs que estão falando da exploração infantil, eu duvido se vc sabe como é fabricada a roupa que vc está usando nesse exato momento!! Se não for igual a Nike, é até pior, porque não é vigiada como a Nike é! [...]. E na hora que uma marca faz uma parada em prol começa o blá-blá! Sai do seu PC e vai lá reclamar na porra do Congresso carai.

Interlocutor 12: A marca já promoveu o encontro inédito do Brown com o Jorge Ben em estúdio, já bancou turnê do Emicida, acabou de bancar o clipe do Criolo e agora fez essa campanha com Emicida, Xará, Don Pixote, Toddy do grupo Opni....e daí vem um cara frustrado aqui chamar os caras de vendidos? PQP, quem é você pra julgar alguém? Deus? Os caras só estão fazendo o trabalho deles, honestamente, divulgando a arte deles e colhendo o que plantaram durante anos ralando...

Interlocutor 13: Ta na Hora de Abrir a mente galera! o Rap Nacional precisa Evoluir e se espandir além da Favela/Comunidade ... Eu torso para o Progresso do Rap deste pais por que ainda é um Rap Limpo e Digno, diferente das dos EUA que já esta Consumado e entregue a Midia Manipuladora, a Nike vendo isso quis inverti em algo que Realmente tem Um proposito Verdadeiro e pé no chão [...].

Os interlocutores acima concordam com o trabalho dos rappers, com o patrocínio da marca e defendem a expansão do rap para além da comunidade. Eles aderem ao discurso da campanha, seja de forma argumentada ou com um tom irônico e agressivo. Para rebater as críticas ao trabalho infantil, o interlocutor 11 sugere que as condições de trabalho nas indústrias de vestuário podem ser até piores do que as da Nike ${ }^{3}$. Há também um ataque em tom irônico aos críticos da parceria rappers/Nike, sugerindo para reclamarem no Congresso Nacional (interlocutor 11), ou desqualificando-os: "frustrados" (interlocutor 12). Já o interlocutor 13 considera o rap brasileiro digno, diferente do rap estadunidense incorporado ao mercado.

Conforme Rotta et al. (2002), esse jogo astucioso e "perigoso" que o hip hop estabelece cada vez mais com a mídia e com o mercado é uma condição de sobrevivência que acompanha a maioria das práticas culturais da cultura urbana atual. No entanto, a supressão de tudo que está fora da cultura comercial, a absorção de todas as formas de arte pelo processo de produção de imagens, é uma das características da pós-modernidade. No atual contexto, a imagem é mercadoria, operando na mesma lógica da produção de mercadorias (JAMESON, 2001).

\section{CONSIDERAÇÕES FINAIS}

A campanha de marketing esportivo "É possível!" se apropria da cultura hip hop e tem como tema a superação das dificuldades no esporte, na arte e na vida. Para isto, utiliza-se de

3 A esse respeito ver Juliboni (2011). 
uma linguagem representativa de uma parcela da população que vive nas periferias e que produz um modo específico de se expressar através do rap, do grafite, do basquete e da dança de rua.

Em relação ao consumo, um tênis pode ser escolhido por diferentes motivos: preço acessível, durabilidade, conforto, qualidade, propriedade (ex. para praticar um esporte), mas também pela marca e seu significado simbólico. No caso analisado, o tênis foi ressignificado como representativo da cultura juvenil da periferia que acredita que "é possível". Embora parte desses jovens seja excluída da cultura de consumo, é inegável o fascínio que esse produto esportivo exerce sobre eles. Vale lembrar a força do consumismo em nossa sociedade:

Essa força suprema é o consumismo, o ponto central de nosso sistema econômico, e também o modo de vida para o qual todos nós somos todos os dias sem cessar treinados por toda nossa cultura de massas e indústria de entretenimento, com uma intensidade de imagens e de mídias sem precedentes na história (JAMESON, 2001, p. 56).

No entanto, por mais poderosos que sejam os discursos que incitam o consumismo, eles têm ainda que se defrontar com a resposta do espectador e com o mundo da experiência (NEWCOMB, 2010), ou seja, com o modo de vida e os valores dos interlocutores. Constatamos que nos comentários dos internautas houve concordância e discordância, total ou parcial, questionamentos, críticas, elogios, sugestões, além de ironias, acusações e debates muito interessantes sobre exploração de trabalho escravo e infantil, as condições de produção das mercadorias, a aliança entre artistas e empresa, a falta de oportunidades de lazer na periferia.

Ainda que o hip hop tenha como objetivo a conscientização e busca da cidadania da juventude excluída, ele não é homogêneo. Há uma vertente cuja tônica é a denúncia e o protesto. Outra, mais "espontânea", parece não ter uma linha política coerente e definida. E outra hegemônica e assimilada pelo mercado, que reproduz os ideais do consumismo, do individualismo e a exaltação da vida privada (ARAÚJO, 2008). Neste estudo nós também identificamos tais divergências, em especial nos comentários dos interlocutores.

Em nossa contemporaneidade, as estratégias de marketing são cada vez mais sedutoras, pois se articulam com a cultura dos diferentes grupos e classes sociais, visando expandir ainda mais o mercado capitalista. Ficou evidente a forte inter-relação entre os aspectos culturais e econômicos em torno da campanha de marketing esportivo. Além disto, constatamos que uma empresa de produtos esportivos está organizando atividades culturais e esportivas na periferia, realizando uma função que deveria ser do Estado. Assim, fica o nosso alerta sobre o perigo dos jovens serem socializados mediados por uma marca, logo, envolvidos em ideais de consumo, antes e acima da necessária compreensão da verdadeira cidadania de uma coletividade.

\section{REFERÊNCIAS}

ARAÚJO, Marianna. Hip-hop: uma batida contra-hegemônica na periferia da sociedade global. In: CONGRESSO BRASILEIRO DE CIÊNCIAS DA COMUNICAÇAO,31. Natal, 2008. Anais... Natal: Intercom: 2008. p. 1-13.

BAKHTIN, Mikhail. Marxismo e Filosofia da Linguagem: problemas fundamentais do método sociológico na ciência da linguagem. 8. ed. São Paulo: Hucitec, 1997.

BAKHTIN, Mikhail. Questões de literatura e de estética: a teoria do romance. São Paulo: Hucitec: UNESP, 1998.

BAKHTIN, Mikhail. Estética da criação verbal. 4. ed. São Paulo: Martins Fontes, 2003.

BAVA, Silvio Caccia. A renda do brasileiro. Le Monde Diplomatique Brasil, n. 53, dez. 2011. 
Disponível em: < https://www.diplomatique.org.br/editorial.php?edicao=53>. Acesso em: 15 jan. 2012.

BRENNER, Anna K.; DAYRELL, Juarez; CARRANO, Paulo. Culturas do lazer e do tempo livre dos jovens brasileiros. In: ABRAMO, Helena Wendel, BRANCO, Pedro Paulo Martoni. (Org.). Retratos da juventude brasileira: análises de uma pesquisa nacional. São Paulo: Fundação Perseu Abramo/ Instituto Cidadania, 2005. p. 175-214.

O QUE você, seu pai e seu avô fazem na Internet. Revista Galileu, Rio de Janeiro, 29 jan. 2013. Disponivel em: <http://revistagalileu.globo.com/Revista/Common/1,EMI329029-17770,00.html>. Acesso em: 15 jan. 2015.

JAMESON, Fredric. A cultura do dinheiro: ensaios sobre a globalização. 2. ed. Petrópolis, RJ: Vozes, 2001.

JULIBONI, Márcio. 6 redes de roupas envolvidas em acusações de trabalho escravo recentemente. Exame.com, Rio de Janeiro, 17 ago. 2011. Disponível em: <http://exame.abril.com.br/negocios/ gestao/noticias/6-redes-de-roupas-envolvidas-em-trabalho-escravo-recentemente>. Acesso em: 15 dez. 2011.

MAGRO, Viviani Melo de Mendonça. Adolescentes como autores de si próprios: cotidiano, educação e o hip hop. Cadernos Cedes, Campinas, v. 22, n. 57, p. 63-75, 2002.

MAINGUENEAU, Dominique. Termos-chave da Análise do Discurso. Belo Horizonte: Ed. UFMG, 2000.

MAINGUENEAU, Dominique. Análise de textos de comunicação. 2 ed. São Paulo: Cortez, 2002.

MAINGUENEAU, Dominique. Gênese dos discursos. Curitiba: Criar Edições, 2005.

MARX, Karl; ENGELS, Friedrich. Manifesto Comunista. São Paulo: Boitempo, 2010.

MELO NETO, F. P. de. Marketing esportivo. Rio de Janeiro: Record, 2003.

NA COLA da China. Isto é dinheiro, Rio de janeiro, 20 out. 2010. Disponível em: http://www. istoedinheiro.com.br/pt/components/news/cmp-news-body/1/5/4251.inc. Acesso em: 2 dez. 2105

NEWCOMB, Horace. Sobre os aspectos dialógicos da comunicação de massa. In: RIBEIRO, Ana Paula Goulart; SACRAMENTO, Igor (orgs.). Mikhail Bakhtin: linguagem, cultura e mídia. São Carlos : Pedro e João Editores, 2010. p. 359-387.

NIKE Sportswear Brasil. Air Force 1 Brasil: vídeo do manifesto É possível! 2011a. Disponível em: <http://www.youtube.com/watch?v=5KOy54-0k6Y>. Acesso em: 1ํo dez. 2011.

NIKE Sportswear Brasil. Air Force 1 Brasil: É possível! 2011b. Disponível em: <http://www.youtube. com/watch?v=49AMUcF1hy8 $>$. Acesso em: 1‥ dez. 2011.

ORLANDI, Eni Puccinelli. Análise de discurso. Campinas, SP: Pontes, 2003.

RECKZIEGUEL, Ana Cecilia de Carvalho; STTIGGER, Marco Paulo. Dança de rua: opção pela dignidade e compromisso social. Movimento, Porto Alegre, v. 11, n. 2, p. 59-73, 2005.

ROTTA, Daltro Cardoso et al. Da produção estética à (re)construção urbana: tatuagens do hip hop. Revista da Educação Física da UEM, Maringá, v. 13, n. 2, p. 97-104, 2002.

SILVA, Carlos Alberto Figueiredo; CORREIA, Adriana Martins. Espetáculo e reflexividade: a dimensão estética do basquete de rua. Revista Brasileira de Ciências do Esporte, Campinas, .v. 30, n. 1, p. 107-122, 2008.

STOPPA, Edmur Antonio. "Tá ligado mano": o hip hop como lazer e busca da cidadania. Tese (Doutorado). 143 f. 2005. Campinas: Universidade Estadual de Campinas, Faculdade de Educação Física, 2005.

WELLER, Wivian. O hip hop como possibilidade de inclusão e enfrentamento da discriminação e da segregação na periferia de São Paulo. Caderno CRH, Salvador, v. 17, n. 40, p. 103-116, 2004. 